\title{
FIRST WORLD GAMES FOR MULTI-DISABLED
}

International Review has reported on a number of occasions the interest displayed by several National Societies in the handicapped persons living in their country. This interest has take the form of a variety of activities and in this connection we published an article in our June 1974 issue on the specific field of sport. The article, describing how the first Stoke Mandeville Games for the paralysed were organized in 1948, also referred to the work of the Junior Section of the Japanese Red Cross (directed by Mrs. Sachiko Hashimoto who was awarded the Henry Dunant Medal in 1971) at the 1964 International Games in Tokyo in the context of the Olympic Games at which hundreds of paraplegics took part.

Mrs. Hashimoto was invited last summer to the First World games for Multi-Disabled organized by the International Sports Organisation for the Disabled (I.S.O.D.) at the Stoke Mandeville Sports Stadium for the Paralyzed and other Disabled, fifty miles from London. We print below extracts from Mrs. Hashimoto's account of the Games.

So far the World Games had been only for paraplegics, but now, for the first time, they were open to the paralyzed and other disabled: the former account for $40 \%$ of all disabled, and the latter, $60 \%$.

"Seeing is believing", and my conviction in the victory of the mind over the weakness of the flesh was strengthened when, watching a totally blind champion participate in the high jump I almost choked with excitement. With his physical limitation he could not run and jump, but stood straight by the bar and touched it softly with his left hand to measure its height. Then, concentration and determination in his expression, he jumped over the bar with a twist of his shoulder and hip only, leaving the bar on the poles. He made it! Of course he tried the higher one next. Another success! I was completely overwhelmed with his accomplishment. All of a sudden, however, my attention was drawn to another man standing quietly behind the champion, that is, his coach. Laurels seemingly decorated the champion, but in heart they were shared by the two, or 
rather the two were united into one in the joy of accomplishing a common goal.

Unity is not uniformity, but symbiosis, each being interdependent as well as independent. Each one has his own role for the common goal. Being human means being incomplete, far from omnipotent in spite of our infinite aspiration. From our painful recognition of human limitation, somehow or other we learn to be humble enough to help and be helped for unity.

In Stoke Mandeville I witnessed an ideal example of success in unity of three persons, Dr. Gutmann (International Review has mentioned in a previous issue that he founded the Games), Miss Joan Scruton and Mr. Charles Atkinson, sports technical expert. They started in a bathroom in 1948, they say. Now simple but sufficient buildings and facilities have been added to the Stoke Mandeville Sports Stadium one by one every year.

In the general assembly held prior to the 1974 Games someone complained about the financial difficulty of developing the National Sports Organization for the Disabled. "Money is lying on the ground. You just do not pick it up", was the prompt reaction of Dr. Gutmann.

Another delegate proposed that each National Sport Organisation for the Disabled should immediately approach the corresponding National Olympic Games Committee, because the next World Games for the Multi-Disabled of I.S.O.D. was to be held in Toronto, Canada, in 1976, following the regular Olympic Games in Montreal, the same year and in the same country. One delegate was against it and said: "Where has the spirit of Coubertin gone? It is right here in our hands! What do we have to go to them for ?" Applause resounded in the hall and echoed in my heart and I said to myself, "The spirit of Henry Dunant is right here !"

The bigger a movement grows in organization and scope, the stronger becomes the temptation for us to depend on its power and status. "The machinery thus built up, having become an end in itself" cuts us off from the spirit of the founder who started with a humble prayer for its birth and his unselfish effort of dedication to the ultimate purpose. In the drama of human life no one should be left out, but each one, should be given a role whether able or disabled, young or aged. In youth programs, for instance, young people are very often entertained as guests; so are the aged and the disabled.

Life is indeed an educational process going through different stages where each one of us is invited only once and for a limited time. Hence the duty of each to play one's role to the full for the survival of mankind, which is the ultimate purpose of the Red Cross in the battlefield and in 
peacetime. It is, however, hardly taught by lip service or beautiful legends of the organization in the past.

Let me quote from Jean Pictet's Red Cross Principles; "If the Red Cross were to lose the human touch, its direct contact with suffering, if it were to lose its voluntary character and become tied up with red tape, it would be like a flower which has been plucked and soon withers and dies." I fully agree with him and have been trying very hard to prepare better learning situations of human touch and direct contact with the disabled for our Junior Red Cross members. But the Red Cross is now quite limited in its supply. There are so many organizations doing programs similar to ours, and even better than ours because they concentrate on one special phase, while we have so widely spread when the world is tending more to technical specialization.

Then why do we not be helped by other specialized groups of the same humanitarian purpose for the good supply of educational opportunities by our helping them? We are now preparing for FESPIC Games for the Disabled (Far Eastern \& South Pacific Games), June 1-3, 1975. This is not a Red Cross project, but we are willing to make our translation and interpretation services available as we did in the Tokyo Paralympics, in 1964.

A volunteer service on a smaller scale and yet of more human touch like this type vitalizes the cells of our large world-wide body of the Red Cross on a symbiotic basis more than our efforts to achieve "admirable statutes, a balanced budget and a well trained staff", etc.

Thought without action is futile.

Action without thought is fatal.

Thought and action combined for Humanity, for anybody, anywhere and any time is the essence of the Red Cross. It must be practised from childhood by Junior Red Cross not for laurels on earth but for the joy of all on earth. 